\title{
Porphyrin Molecules Decorated on Metal-Organic Frameworks for Multi-Functional Biomedical Applications
}

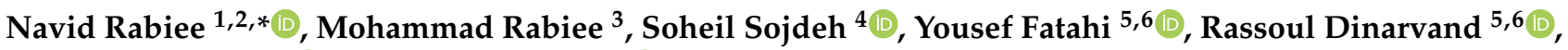

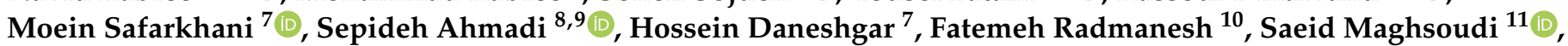 \\ Mojtaba Bagherzadeh ${ }^{7}$, Rajender S. Varma ${ }^{12, *(1)}$ and Ebrahim Mostafavi ${ }^{13,14, * \mathbb{C}}$
}

1 Department of Physics, Sharif University of Technology, Tehran 11155-9161, Iran

2 School of Engineering, Macquarie University, Sydney, NSW 2109, Australia

3 Biomaterial Group, Department of Biomedical Engineering, Amirkabir University of Technology, Tehran 15875-4413, Iran; mrabiee@aut.ac.ir

4 School of Chemistry, College of Science, University of Tehran, Tehran 14155-6455, Iran; sojdesoheil@gmail.com

5 Department of Pharmaceutical Nanotechnology, Faculty of Pharmacy, Tehran University of Medical Sciences, Tehran 14155-6451, Iran; youseffatahi@gmail.com (Y.F.); dinarvand@tums.ac.ir (R.D.)

6 Nanotechnology Research Center, Faculty of Pharmacy, Tehran University of Medical Sciences, Tehran 14155-6451, Iran

check for updates

Citation: Rabiee, N.; Rabiee, M.;

Sojdeh, S.; Fatahi, Y.; Dinarvand, R.; Safarkhani, M.; Ahmadi, S.; Daneshgar, H.; Radmanesh, F.; Maghsoudi, S.; et al. Porphyrin Molecules Decorated on

Metal-Organic Frameworks for Multi-Functional Biomedical Applications. Biomolecules 2021, 11, 1714. https://doi.org/10.3390/ biom 11111714

Academic Editors: Chia-Hao Su, Fong-Yu Cheng and Chien-Chih Ke

Received: 22 October 2021

Accepted: 15 November 2021

Published: 17 November 2021

Publisher's Note: MDPI stays neutral with regard to jurisdictional claims in published maps and institutional affiliations.

Copyright: (c) 2021 by the authors. Licensee MDPI, Basel, Switzerland. This article is an open access article distributed under the terms and conditions of the Creative Commons Attribution (CC BY) license (https:/ / creativecommons.org/licenses/by/ $4.0 /)$.
7 Department of Chemistry, Sharif University of Technology, Tehran 11155-3516, Iran; moein.s.1991@gmail.com (M.S.); daneshgar.ho@gmail.com (H.D.); m.bagherzadeh.sharif@gmail.com (M.B.)

8 Student Research Committee, Department of Medical Biotechnology, School of Advanced Technologies in Medicine, Shahid Beheshti University of Medical Sciences, Tehran 19857-17443, Iran; speahmadi@yahoo.com

9 Cellular and Molecular Biology Research Center, Shahid Beheshti University of Medical Sciences, Tehran 19857-17443, Iran

10 Uro-Oncology Research Center, Tehran University of Medical Sciences, Tehran 14197-33141, Iran; rad.biotech89@gmail.com

11 Faculty of Medicine, Department of Physiology and Pathophysiology, University of Manitoba, Winnipeg, MB R2H 0G1, Canada; maghsous@myumanitoba.ca

12 Regional Centre of Advanced Technologies and Materials, Czech Advanced Technology and Research Institute, Palacky University, Šlechtitelů 27, 78371 Olomouc, Czech Republic

13 Stanford Cardiovascular Institute, Stanford University School of Medicine, Stanford, CA 94305, USA

14 Department of Medicine, Stanford University School of Medicine, Stanford, CA 94305, USA

* Correspondence: nrabiee94@gmail.com or navid.rabiee@mq.edu.au (N.R.); varma.rajender@epa.gov (R.S.V.); ebimsv@stanford.edu or ebi.mostafavi@gmail.com (E.M.)

Abstract: Metal-organic frameworks (MOFs) have been widely used as porous nanomaterials for different applications ranging from industrial to biomedicals. An unpredictable one-pot method is introduced to synthesize $\mathrm{NH}_{2}$-MIL-53 assisted by high-gravity in a greener media for the first time. Then, porphyrins were deployed to adorn the surface of MOF to increase the sensitivity of the prepared nanocomposite to the genetic materials and in-situ cellular protein structures. The hydrogen bond formation between genetic domains and the porphyrin' nitrogen as well as the surface hydroxyl groups is equally probable and could be considered a milestone in chemical physics and physical chemistry for biomedical applications. In this context, the role of incorporating different forms of porphyrins, their relationship with the final surface morphology, and their drug/gene loading efficiency were investigated to provide a predictable pattern in regard to the previous works. The conceptual phenomenon was optimized to increase the interactions between the biomolecules and the substrate by reaching the limit of detection to $10 \mathrm{pM}$ for the Anti-cas9 protein, $20 \mathrm{pM}$ for the single-stranded DNA (ssDNA), below 10 pM for the single guide RNA (sgRNA) and also around $10 \mathrm{nM}$ for recombinant SARS-CoV-2 spike antigen. Also, the MTT assay showed acceptable relative cell viability of more than $85 \%$ in most cases, even by increasing the dose of the prepared nanostructures.

Keywords: gene delivery; CRISPR; biosensor; biomedicine; MOF; COVID-19 


\section{Introduction}

The study of biological properties along with chemical and physical optimizations on a molecular scale has been conducted by several techniques, and they have made significant advancements over time, leading to enhanced accuracy [1-3]. However, this enhancement has brought about a significant increase in cost and time, in particular for biomedical studies that are being conducted through expensive and high-precision techniques. In many cases, unfortunately, these features can stop this research from entering into the clinical phase. Therefore, it is imperative that special attention be paid to the maximum use of simple systems, but within the limits of acceptable standards [4-12]. So far, there have been very limited works that deal with sustainable chemistry and circular economy in their concepts, even in the biomedical sciences. This scientific area has reached a new phase of advancements; however, the cost of preparation of the pre-clinical and clinical materials causes these steps to be a luxury method. Therefore, scientists should focus more on using precisely sustainable chemistry and circular economy rules [13-17].

To date, in various fields of basic sciences, especially chemistry and physics, standards have been set for low-cost optimizations and early conclusions. However, in biomedical studies, no specific standards have yet been defined. The need for early decisions on methods, approaches, or even groups of synthetic chemical compounds deployed for biomedical applications makes tremendous sense. In the meantime, such standards can also help research advance more expeditiously and efficiently. Our aim in this study is to focus on establishing a physicochemical standard for smart cargo delivery in inorganic systems [18-25]. Also, interdisciplinary researchers could be considered a tool for rapid movements and advancements to the early diagnosis and detection of different kinds of diseases, pathogens, and biomarkers. One of the overlooked facts regarding the research in this field is the importance of rapid and early diagnosis as well as the detections through simple, green, and cost-effective methods. Therefore, one of the most important aspects of this work is to develop a nanosystem via a simple, environmentally friendly, and costeffective method for highly advanced diagnosis and detection systems [26-30]. MOFs, due to their high porosity, surface functionalizations, and biodegradable bulk properties, as well as their different sized particles, channels, and pores, have gained scientists' attention. In this regard, different forms of MOFs have been synthesized and characterized for different biomedical applications; however, using MOFs as a substrate would be a wise choice rather than using them as an active probe. Recently, we used UiO-66-based nanomaterials for co-delivery of a drug and a genetic material (Doxorubicin and pCRISPR) and showed that the surface of the MOF could be decorated with different types of biodegradable polymers as well as the leaf extracts. Therefore, it should be possible to form different types of nanocomposites with inorganic and organic components [31-33].

Many autoimmune diseases, and even genetic and acute infectious diseases, can be diagnosed by very small changes in the number of bioactive molecules in biological fluids, including blood. To this end, early detection of very small changes in the concentration and even the number of bioactive molecules in biological fluids can be very significant. In the case of cancer, there are substantial changes in vitamins and even natural proteins, which can be detected in the early stages. In the case of other acute diseases, these changes can lead to alterations in genetic structures and even in the presence of certain biomolecules. However, the main problem here is the early detection of the variations and associated biomolecules. Electrochemical sensors are now widely and routinely used for early detection. Nevertheless, the ease of operation, cost-effectiveness, simple optimization, and reliability of optical sensors are not comparable to electrochemical types. Therefore, the development of innovative technologies in optical sensors can give rise to the emergence of new and reliable methods. To date, no specific research has been conducted on the detection and identification of biomolecules and proteins having both selectivity and sensitivity towards all of the anti-cas9 protein, ssDNA, and sgRNA; conducted studies are based on the development of electrochemical methods that require special equipment, and are not easily developed to point-of-care devices [34-42]. In order to prepare an advanced sensitive 
nanomaterial with multi biofunctional applications, two crucial parameters should be taken into account. The first is to possess a suitable, highly porous biocompatible, and tunable substrate, which in this case, a MOF has been selected. The second aspect concerns using a highly sensitive molecule as a sensitizer, for which a porphyrin has been selected due to its considerable biocompatibility, quantum yield, and significant quantum lifetime [31,43-45].

This work aims to design, synthesize, and characterize a cost-effective and greener MOF and investigate their surface morphology and potential relationships with the biological properties. Further, with the objective of an early decision on the biomedical features of the synthesized nanocomposite, we exclusively focused on morphological analysis. The MOF was adorned with phthalocyanine-like molecules (porphyrin) to enhance the sensitivity of the nanomaterial towards different biomolecules. In this manner, field emission electron microscopy (FESEM), transmission electron microscopy (TEM), and atomic force microscopy (AFM) analysis were conducted, and the results were analyzed based on them. In the next step, the sensitivity of the synthesized nanomaterials in the presence of ssDNA, sgRNA, and Anti-cas9 protein was investigated through screening the fluorescence spectra of the surface decorated porphyrins. Also, the relative cell viability of the synthesized nanomaterials was investigated comprehensively via MTT assay on the HEK-293, HeLa, HepG2, and PC12 cell lines after 24 and 48 h of treatment.

\section{Methods}

\subsection{Synthesis of NH2-MIL-53 via High-Gravity Technique}

The synthesis concept for $\mathrm{NH}_{2}-\mathrm{MIL}-53$ is based on the preceding literature [46,47]. However, in this work, a new synthesis procedure is developed with the assistance of a high-gravity technique and deploying the green chemistry approach adapted from our previous works [21,48,49]. Briefly (as depicted in Figure 1), $2.3 \mathrm{mmol}$ of $\mathrm{CrCl}_{3} \cdot 6 \mathrm{H}_{2} \mathrm{O}$ (SigmaAldrich, Germany) and $2.3 \mathrm{mmol}$ of 2-aminoterphtalic acid $\left(\mathrm{H}_{2} \mathrm{BDC}-\mathrm{NH}_{2}\right)$ (Sigma-Aldrich, Germany) were mixed and transferred to a $100 \mathrm{~mL}$ jar, and the mixture was dissolved by the addition of $85 \mathrm{~mL}$ of water/ethanol (1:1) and $1 \mathrm{~mL}$ of formic acid (Sigma-Aldrich, Germany). In this step, the modified rotating packed bed (RPB) system was applied as described in our previous articles [50], which has a sealed ring and a packed rotator, and a jacket for temperature control, as well as the necessary inlets and outlets. For the synthesis procedure, the solution mixture was transferred to the internal circulation space of the RPB system through the inlet. The rotation of this RPB system was adjusted to $1400 \mathrm{rpm}$, which resulted in a high-gravity factor of 182 . The temperature of the RPB system was adjusted to $62{ }^{\circ} \mathrm{C}$ (that is more than $10{ }^{\circ} \mathrm{C}$ below the typical reaction protocols [51,52]), and the internal space of the RPB was degassed by flowing the oxygen for $1.5 \mathrm{~h}$ prior to starting the system. After about $1.5 \mathrm{~h}$ (which is also $2 \mathrm{~h}$ below the typical reaction $[51,53]$ ), the samples were cooled down to room temperature under the gas flow of $\mathrm{NH}_{3}$, and after that, the central system of RPB was degassed with the $\mathrm{N}_{2}$ prior to collecting the synthesized nanomaterial. Then, the synthesized MOF was placed in a solution containing $1.5 \mathrm{~g}$ of Rosmarinus officinalis (leaf extracts) to modify the surface; the suspension was stirred for $6 \mathrm{~h}$ at room temperature.

\subsection{Fabrication of Nanomaterial for Biomedical Assay}

In order to prepare the suitable nanomaterial for biomedical assay, the synthesized $\mathrm{H}_{2} \mathrm{TMP}(3 \mathrm{mg})$ was dispersed into DMF $(10 \mathrm{~mL})$ and sonicated in a dark place for $17 \mathrm{~min}$, and then the modified MOF $(8 \mathrm{mg})$ was added to the mixture. The final mixture was stirred for $24 \mathrm{~h}$ in a dark place at room temperature. 


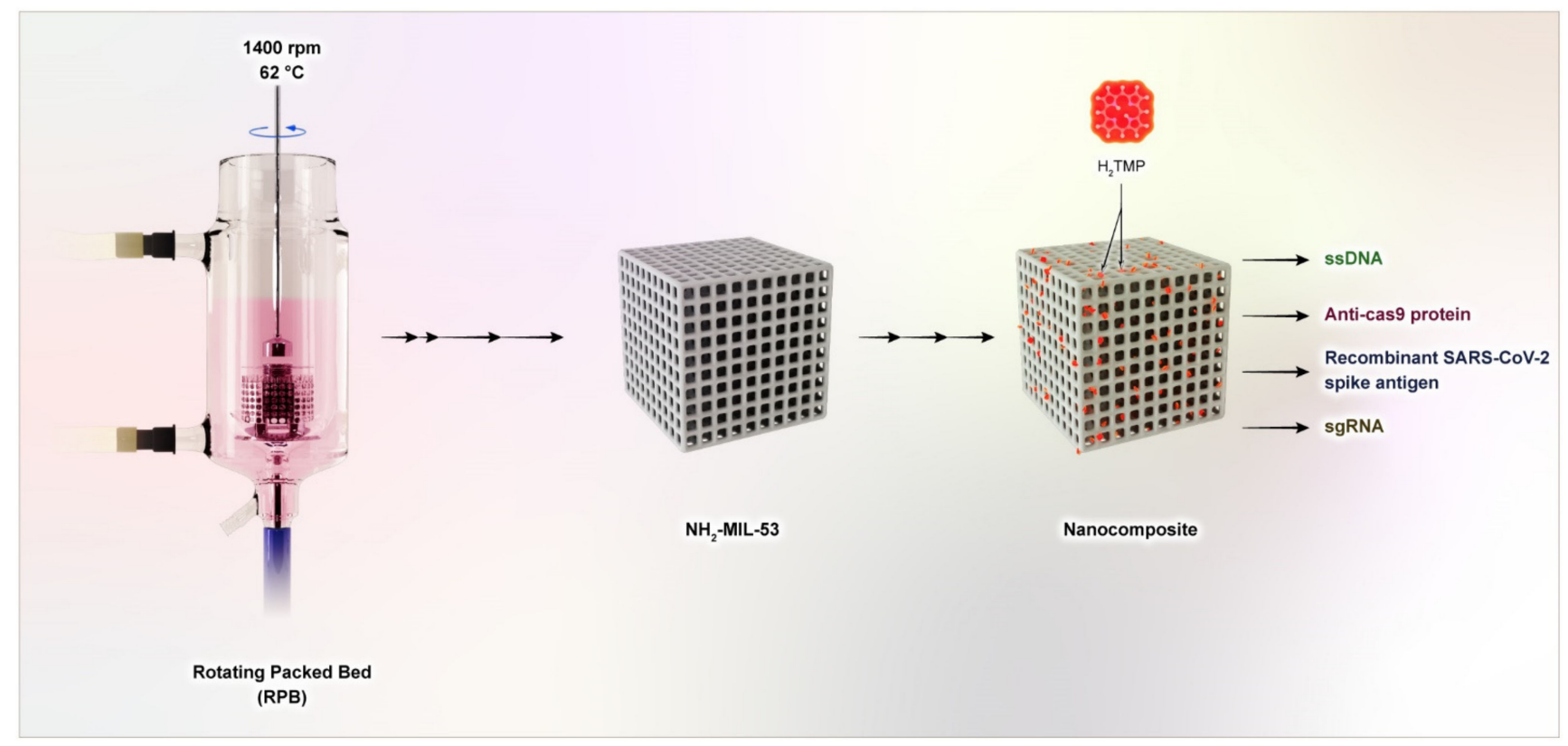

Figure 1. A schematic illustration of the synthesis and preparation of the MOF-based nanocomposite with the assistance of a high-gravity technique.

\subsection{Cytotoxicity Analysis}

First, all of the materials and nanomaterials were sterilized using ultraviolet exposure. Then, in order to assess the relative cell viability, a cytocompatibility assessment was conducted using MTT (3-[4,5-dimethylthiazol-2-yl]-2,5-diphenyltetrazolium bromide) (MTT, Sigma, Germany) colorimetric assay at three different time points of 24, 48, and $72 \mathrm{~h}$. In this regard, four kinds of cell lines, including PC12 cells (ATCC CRL-1721 ${ }^{\text {TM}}$ ), HEK-293 (ATCC CRL-1721 ${ }^{\mathrm{TM}}$ ), HeLa (ATCC CCL-2), and HepG2 (ATCC HB 8065), were applied. Briefly, $1 \times 10^{5}$ cells per well were cultured on the substrate in Dulbecco's Modified Eagle's Medium (DMEM, Gibco, Germany) containing $100 \mathrm{IU} / \mathrm{mL}$ streptomycin and $100 \mathrm{IU} / \mathrm{mL}$ penicillin (Invitrogen, Germany), and 10\% fetal bovine serum (FBS; Gibco, Germany), and then, the resultants were incubated at the normal condition $\left(37^{\circ} \mathrm{C}\right.$ at $\left.5 \% \mathrm{CO}_{2}\right)$. After that, $100 \mu \mathrm{L}$ of the MTT solution ( $5 \mathrm{mg} / \mathrm{mL}$ in PBS) was added to each well, and then, the medium was replaced with the formazone precipitates (dissolved in dimethyl sulfoxide (DMSO; Sigma-Aldrich, Germany). The optical absorbance was measured at $570 \mathrm{~nm}$ using a microplate Elisa reader (ELX808, BioTek, Germany).

2.4. Investigation of the ssDNA, sgRNA, Anti-cas9 Protein, and Recombinant SARS-CoV-2 Spike Antigen Interaction with the Modified Nanocomposite

In order to analyze the possible interaction between the ssDNA (the sequence of the used ssDNA was 5'-SH-( CH $\left._{2}\right)_{6}$-TGT GGG GGT GGA CGG GCC GGG TAGA-3'), sgRNA, Anti-cas 9 protein, and recombinant SARS-CoV-2 spike antigen and the synthesized MOF, $100 \mu \mathrm{L}$ of the MOF-porphyrin (with the concentration of $10 \mathrm{mg} / \mathrm{mL}$ ) (as the number 1 concentration (main concentration)) and $40 \mu \mathrm{L}$ of analyte (as the number 1 concentration (main concentration)) were incubated for $30 \mathrm{~min}$ at $3{ }^{\circ} \mathrm{C}$. Different concentrations of the prepared host-guest molecules were prepared as depicted in the main text image. These complexes were purified by centrifuging at 14,000 rpm for $10 \mathrm{~min}$. In the next step, the precipitates were dissolved in ultrapure water and washed with an excess amount of water.

\section{Results and Discussion}

As mentioned in the introduction, the aim of this project is to establish a standard for predicting the biological properties through minimal identification of synthesized nanomaterials. For this purpose, in this project, only surface characterizations were used 
to accurately understand the surface morphology. The FESEM images (Figure 2A,B) show that the cubic and semi-cubic nanostructures that stand for the MOF appeared with lots of aggregations that originated from the presence of leaf extracts. In this study, the aim was to use a MOF-based nanostructure without any extensive purifications, synthesized with the assistance of green media for biomedical applications. Therefore, these aggregations were not detected as a negative result for this kind of study. The TEM images (Figure 2C,D,G) showed the cubic nanostructural morphology of the MOF clearly, with a sharp naturalbased coating on the edges of these MOF's. The size of the MOF is in the range of 40 to $70 \mathrm{~nm}$, which is suitable for biomedical applications. The results of the AFM investigations (Figure 2E,F) showed aggregations and agglomerations in some of the sites, but most of the surfaces were free of any chemical and/or physical molecular stackings. Also, the roughness of these MOF-based surfaces (Figure 3A-D) is not homogenized and could result in the physical interaction between different biomolecules and genetic materials with these surfaces. These physical interactions could happen through the small protein-based domains in the biomolecules and the roughness of more than $8 \mathrm{~nm}$, but for some of the genetic materials, these interactions in the presence of roughness more than $5 \mathrm{~nm}$ have been observed as well [54-56]. To ascertain the successful synthesis of the MOF's, the powder X-ray diffraction (PXRD) and Fourier transform infrared spectroscopy (FTIR) was performed (Supplementary Materials Figures S1 and S2), and the results were compared to the literature, which affirmed the successful synthesis of the MOF. Additionally, appropriate elemental mapping of the synthesized MOF assisted by high-gravity and the deployment of leaf extracts was conducted. The results (Supplementary Materials Figure S3) indicated the presence of the main elements on the surface of the green synthesized MOF.
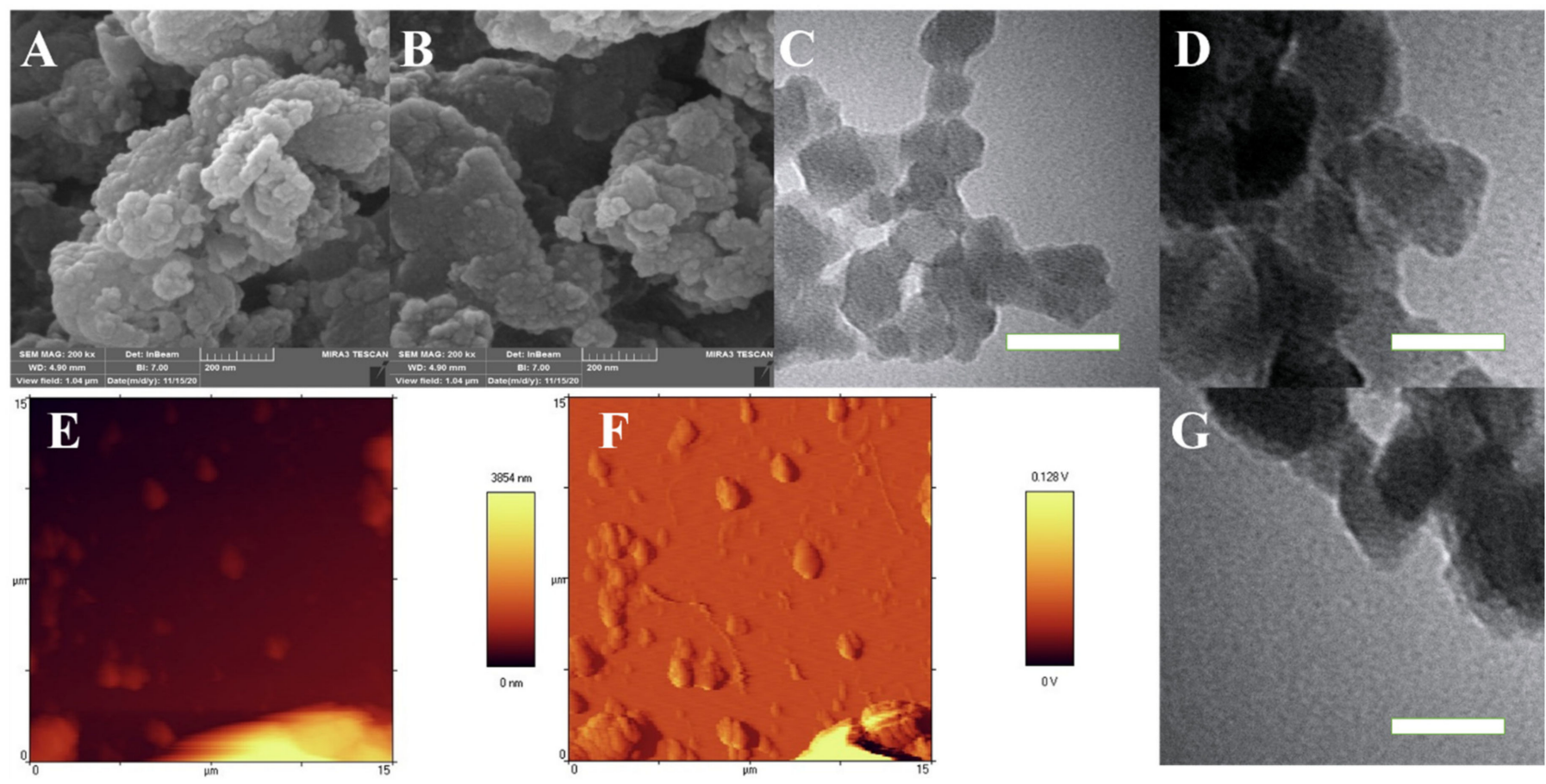

Figure 2. FESEM (A,B) (from different places to prove the homogeneity of the nanostructure), TEM (C,D,G) (from different places to prove the homogeneity of the nanostructure), and 2D AFM (E,F) (from different places to prove the homogeneity of the nanostructure) results of the NH2-MIL-53@H2TMP. Scale bar of the TEM images is $80 \mathrm{~nm}$. 


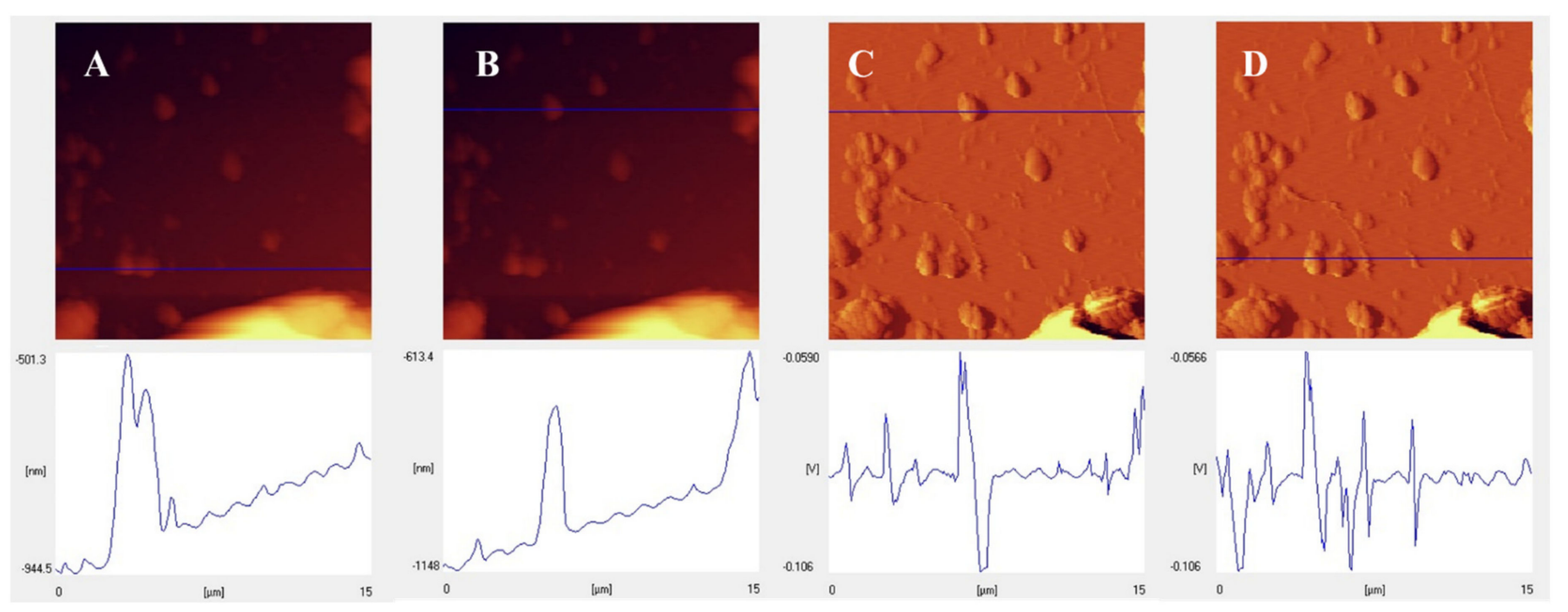

Figure 3. Line analysis roughness with different positions (A-D) images of the $\mathrm{NH}_{2}-\mathrm{MIL}-53 @ \mathrm{H}_{2} \mathrm{TMP}$.

After the surface characterizations of the $\mathrm{NH}_{2}-\mathrm{MIL}-53 @ \mathrm{H}_{2} \mathrm{TMP}$, the cellular toxicity of these nanomaterials was investigated on the HEK-293, HeLa, HepG2, and PC12 cell lines after 24 and $48 \mathrm{~h}$ of treatments. Six different concentrations of the nanomaterials, $\mathrm{H}_{2} \mathrm{TMP}$, $\mathrm{NH}_{2}-\mathrm{MIL}-53$, and $\mathrm{NH}_{2}-\mathrm{MIL}-53 @ \mathrm{H}_{2} \mathrm{TMP}$, ranging from 0.1 to $50 \mathrm{mg} / \mathrm{mL}$, were investigated. The median cell viability results (Figure 4 ) showed that most of the synthesized nanomaterials had a relative cell viability of more than $90 \%$ in most cases; however, the relative cell viability of the pure MOF was lower than that of porphyrin and the related nanocomposite. Also, the dose-dependent MTT results (Figure 5) indicated that by increasing the concentration of the nanomaterials, the cell viability decreased in all cases. The decreasing rate on the concentrations below $10 \mathrm{mg} / \mathrm{mL}$ is much higher than above $10 \mathrm{mg} / \mathrm{mL}$, which is a good result. These types of nanomaterials can be applied as the scaffolds and the implants in order to deliver a specific drug or sensitizer to a specific and targeted tissue, which is mostly the skin. Such nanomaterials can be adjusted to encapsulate a therapeutic and facilitate its release on tumor sites or any targeted cells [57-59]. Therefore, they should have significantly high relative cell viability. In the case of photodynamic therapy and photothermal therapy appliances, these types of carriers and/or implants should have relative cell viability of more than $82 \%$ on those 4 mentioned cell lines $[48,60,61]$. For the drug/gene delivery applications, the relative cell viability ideally should be higher than the encapsulated cargo (drug or genetic material); for instance, for targeted delivery of doxorubicin or azithromycin and related therapeutics, the nano-carrier cell viability should be higher than $60 \%$ on the HEK-293, MCF-7, HeLa, and PC12 [62-65]. In this study, the aim of surface modification of the nanomaterials with porphyrin was to increase their sensitivity towards different biomolecules and deployment of the ensuing system for biosensor applications due to the intrinsic feature of the porphyrin to different types of stimuli like hydrogen peroxide and even different metal-free coordinations. Interestingly, the MTT results clearly showed that (Figure 6) by decorating the MOF nanostructures with porphyrin, the relative cell viability increased substantially due to the biomimetic chemistry nature of the porphyrins, same as the hemoglobin and other types of physiological smalland macromolecules, and the final nanoplatforms (or nano-carriers/nanosystems) were turned to a biocompatible form. 

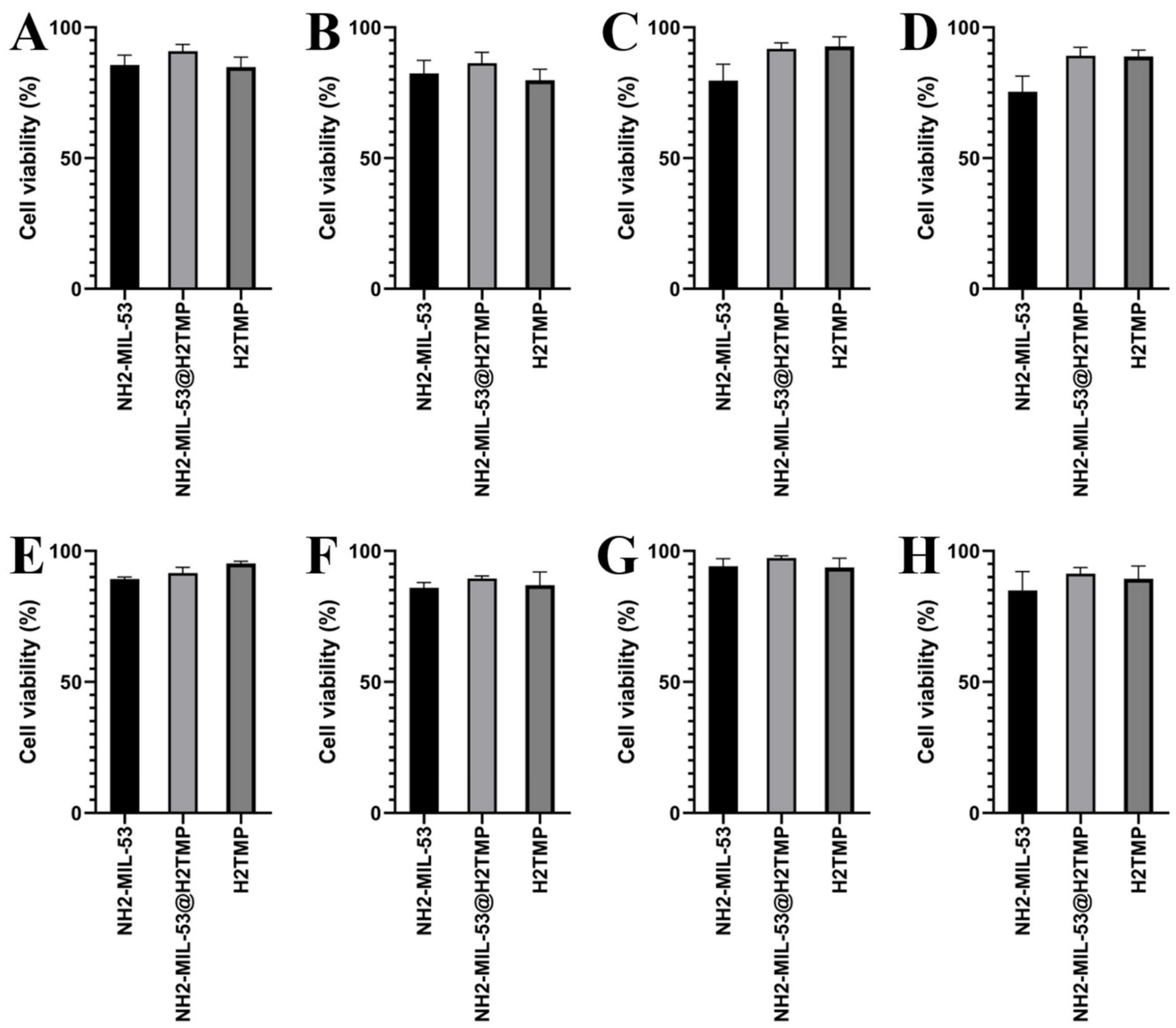

Figure 4. MTT results (with the median values) of the synthesized nanomaterials on the HEK-293 (A,B), HeLa (C,D), HepG2 $(\mathbf{E}, \mathbf{F})$, and PC12 $(\mathbf{G}, \mathbf{H})$ after (24 and 48$)$ hours of treatment, respectively. The data shown here are represented by the median values, and the exact concentrations appear in Figure 4. 
HEK-293 24h

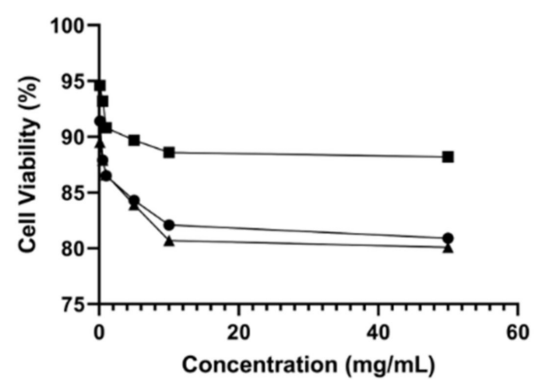

HeLa 24h

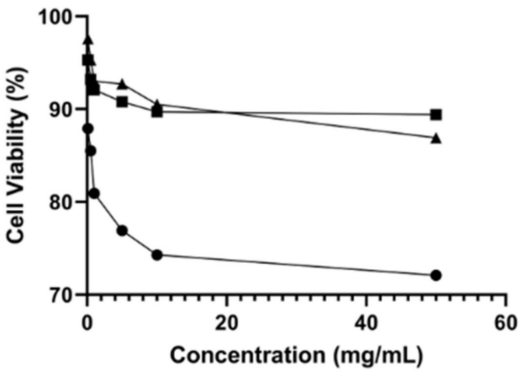

HepG2 24h

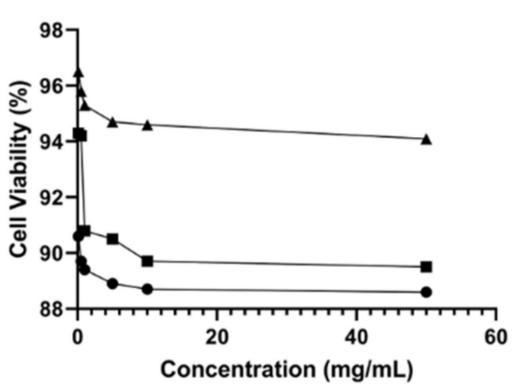

PC12 24h

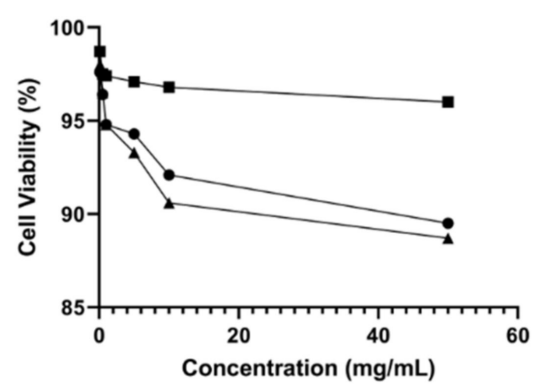

HEK-293 48h

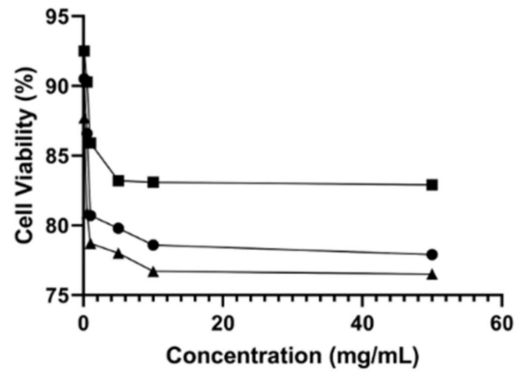

HeLa 48h

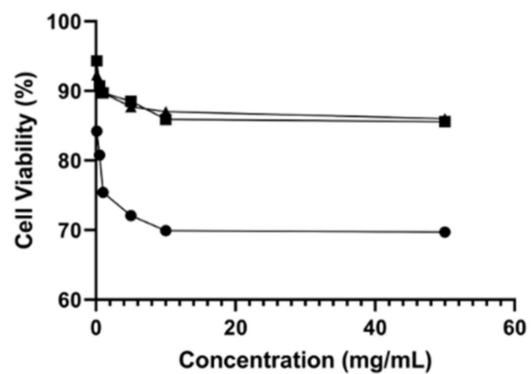

HepG2 48h

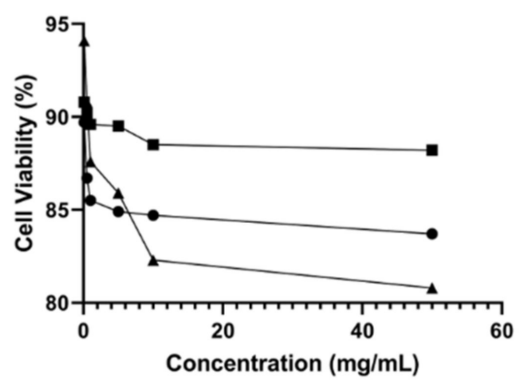

PC12 48h

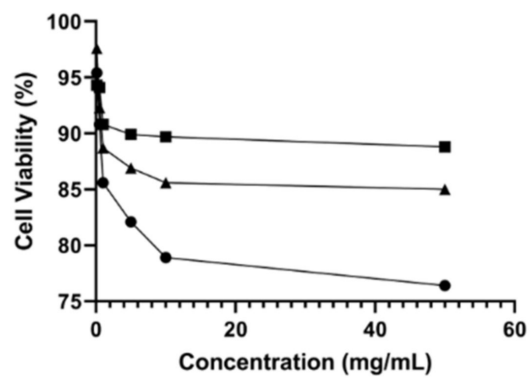

-- NH2-MIL-53

- NH2-MIL-53@H2TMP

- H2TMP

Figure 5. Dose-dependent MTT results of the synthesized nanomaterials. 
A

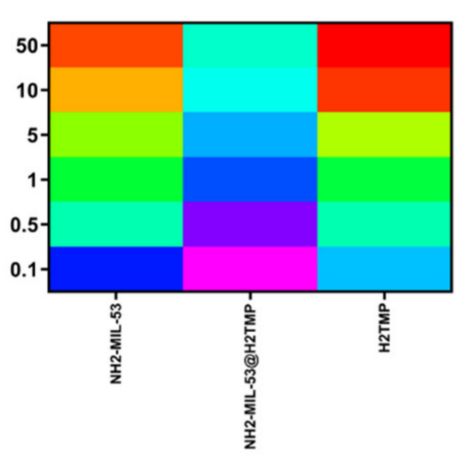

D

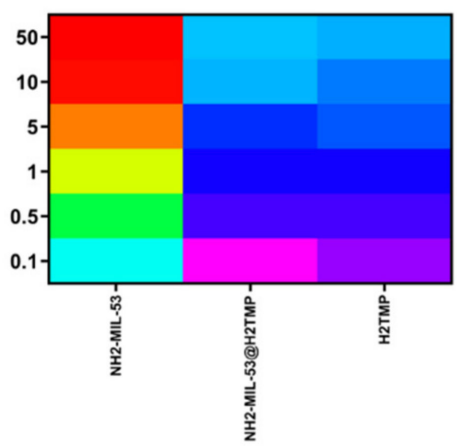

G

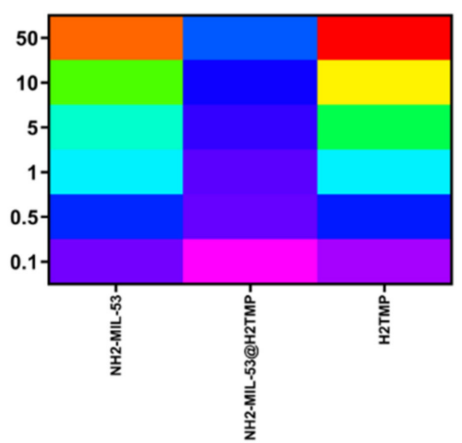

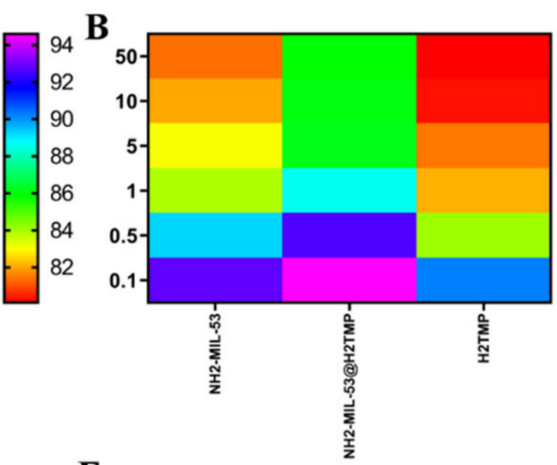

E

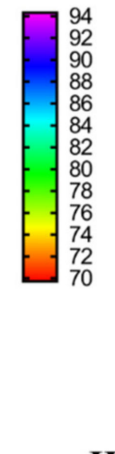

\section{H}
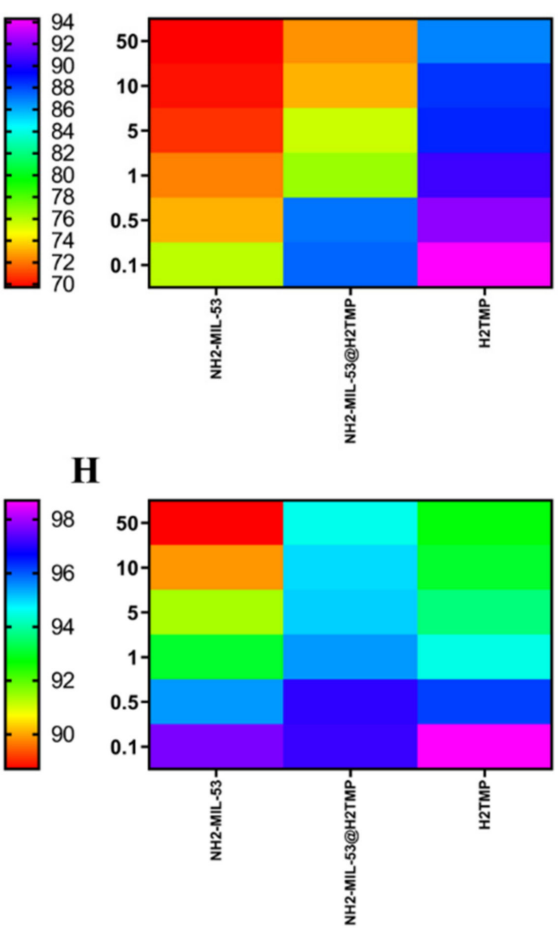

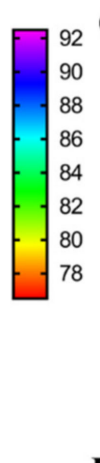

$\mathbf{F}$
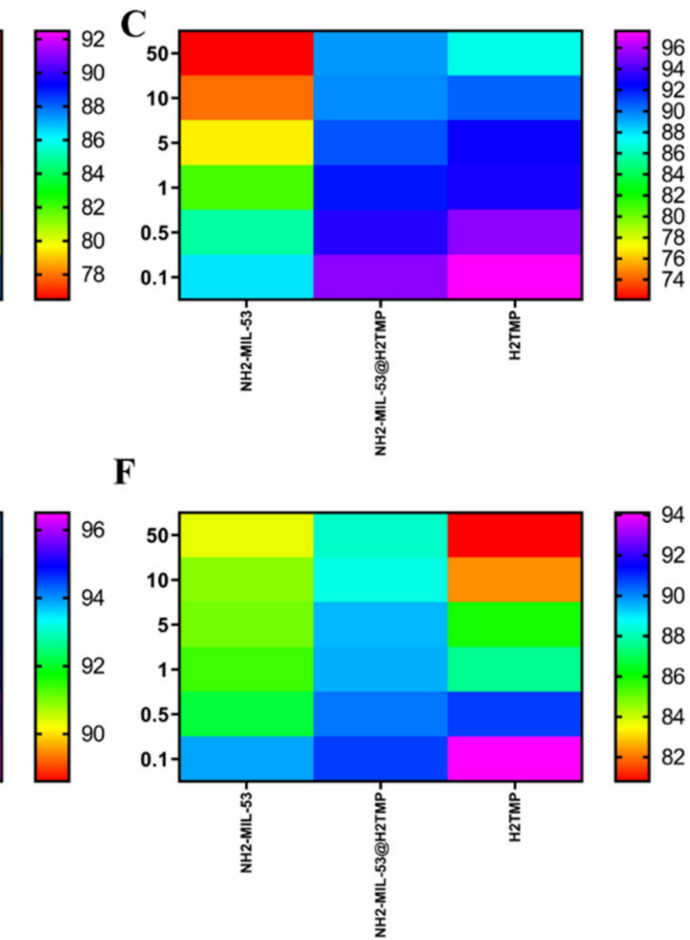

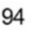

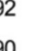

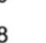

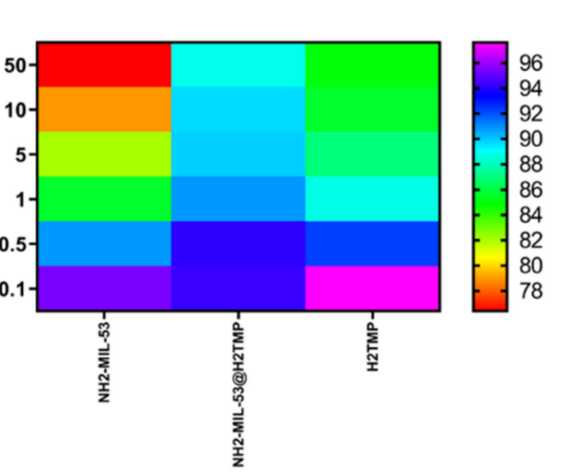

Figure 6. MTT results (dose-dependent with the heat-map shape) of the synthesized nanomaterials on the HEK-293 (A,B), HeLa (C,D), HepG2 (E,F), and PC12 (G,H) after (24 and 48) hours of treatment, respectively.

Also, in order to determine the possible interactions with the cell membranes and its relationship with the destructive/negative effects on the in vitro cellular experiments, the $\mathrm{NH}_{2}-\mathrm{MIL}-53 @ \mathrm{H}_{2} \mathrm{TMP}$ was exposed to MCF-7 cell line (stained with 4',6-diamidino-2phenylindole (DAPI)) for $48 \mathrm{~h}$, and the morphology of the cells was investigated by confocal laser scanning microscopy (CLSM). The results showed that (Figure 7) the synthesizeddecorated MOF does not have any significant cytotoxicity to the cancerous cell line; therefore, the morphology of the stained cells did not change. 


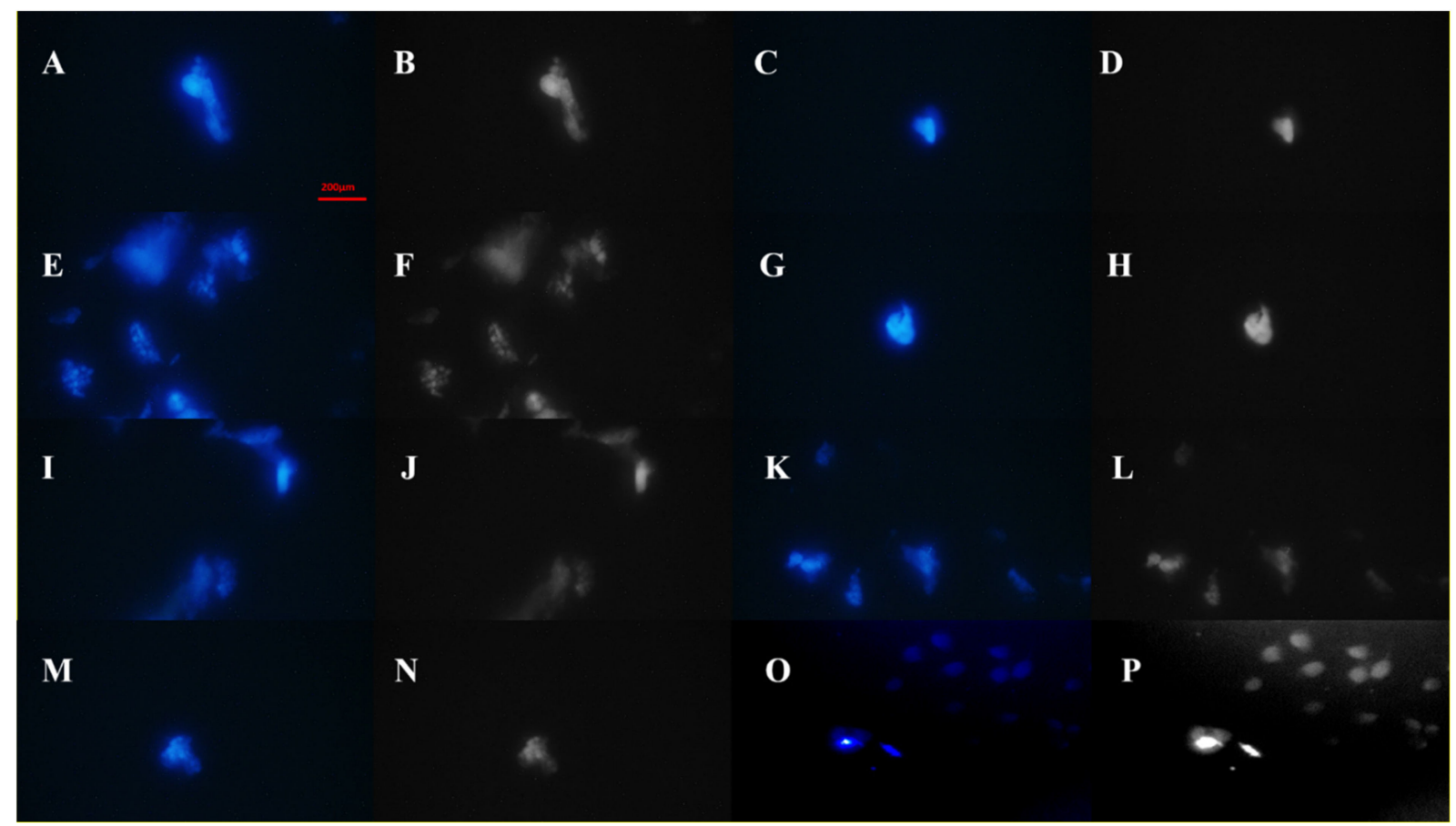

Figure 7. CLSM images of the MCF-7 cell line treated with $\mathrm{NH}_{2}-\mathrm{MIL}-53 @ \mathrm{H}_{2} \mathrm{TMP}(\mathrm{A}-\mathbf{N})$ after $48 \mathrm{~h}$ of treatment and the control group $(\mathbf{O}, \mathbf{P})$. The gray-scale images of the treated DAPI-stained MCF-7 cell lines $(\mathbf{B}, \mathbf{D}, \mathbf{F}, \mathbf{H}, \mathbf{J}, \mathbf{L}, \mathbf{N}, \mathbf{P})$ in order to show the exact morphology of the cells.

In order to determine the possible interactions between the $\mathrm{NH}_{2}-\mathrm{MIL}-53 @ \mathrm{H}_{2} \mathrm{TMP}$ and different genetic materials and proteins, fluorescence spectroscopy was used. In this context, three different analytes, ssDNA, sgRNA, and Anti-cas9 protein, were selected, and their limit of detection with different concentrations was investigated. Both porphyrin and the MOF are fluorescence active, and they have fluorescence spectra in the range of 400 to $500 \mathrm{~nm}$. However, by coupling these nanostructures via a high-gravity and green approach, a strong fluorescence emission absorbance at around $440 \mathrm{~nm}$ was observed (Figure 8). The used porphyrin, $\mathrm{H}_{2} \mathrm{TMP}$, has a rigid structure; therefore, its conformation is not affected by phase changes and/or solvent changes. In this experiment, the possible interaction and detection ability of the nanomaterial in the presence of those 3 analytes was investigated in the range of 10 to $500 \mathrm{pM}$ of the analytes. Based on the literature, there are limited studies using simple, cost-effective, and tunable nanomaterial to detect trace amounts of those three analytes. Therefore, the detection range of 10 to $500 \mathrm{pM}$ is highly competitive and can be considered as an advantage. By the addition of different concentrations of Anti-cas9 protein to the substrate, the fluorescence spectra decay in a predictable manner with a linear slope; therefore, this detection method can be used for clinical trials. The presence of Anti-cas9 proteins in the samples of animals and/or humans could lead to several mutations as well as severe diseases. Thus, ultrasensitive methods to detect low concentrations of these proteins can help medical doctors for the early diagnosis of different types of mutations and diseases. By the addition of different concentrations of sgRNA and ssDNA, the observed fluorescence decay was different. In the presence of these two analytes, a very fast fluorescence decay after the addition of $30 \mathrm{pM}$ of the analytes was screened, which would be because of the spatial coordination, interactions and/or inhibition around the porphyrin rings [66]. Further, these sequences of genetic materials could fold the whole of the nanostructures, including MOF; therefore, they will affect the MOF spectra as well as the porphyrin at one time. However, all these observations indicate that the $\mathrm{NH}_{2}-\mathrm{MIL}-53 @ \mathrm{H}_{2} \mathrm{TMP}$ can detect trace concentrations of Anti-cas9 protein, ssDNA, and sgRNA, which is a promising method with easily synthesized, cost-effective and green nanomaterial. 

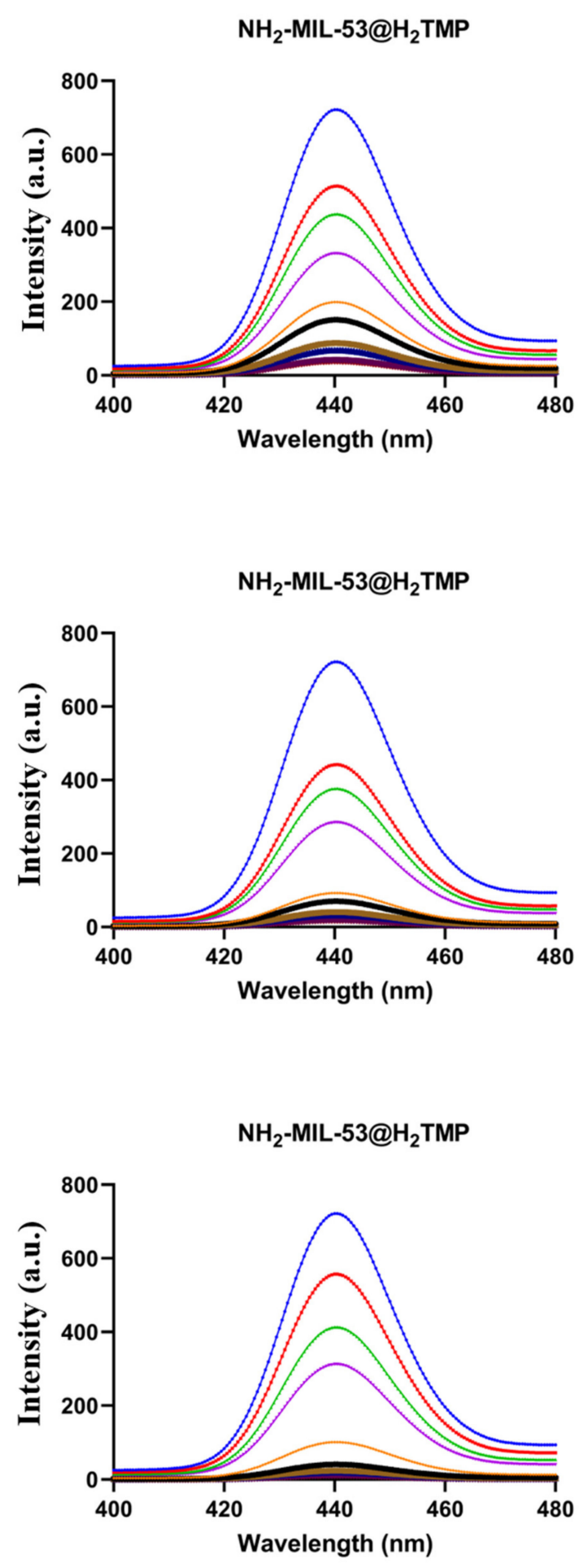

Anti-cas 9 protein

- Control

- $10 \mathrm{pM}$

- $20 \mathrm{pM}$

- $30 \mathrm{pM}$

- $50 \mathrm{pM}$

$\rightarrow 100 \mathrm{pM}$

$=200 \mathrm{pM}$

$\leftarrow 250 \mathrm{pM}$

$\rightarrow 300 \mathrm{pM}$

$\rightarrow 500 \mathrm{pM}$

sgRNA

- Control

- $10 \mathrm{pM}$

$-20 \mathrm{pM}$

- $30 \mathrm{pM}$

- $50 \mathrm{pM}$

$\rightarrow 100 \mathrm{pM}$

$=200 \mathrm{pM}$

$\leftarrow 250 \mathrm{pM}$

$\rightarrow 300 \mathrm{pM}$

$\rightarrow 500 \mathrm{pM}$

$$
\begin{aligned}
& \text { ssDNA } \\
& -\quad \text { Control } \\
& -10 \mathrm{pM} \\
& -\quad 20 \mathrm{pM} \\
& -30 \mathrm{pM} \\
& -50 \mathrm{pM} \\
& \rightarrow \quad 100 \mathrm{pM} \\
& -200 \mathrm{pM} \\
& -250 \mathrm{pM} \\
& \rightarrow \quad 300 \mathrm{pM} \\
& \rightarrow-500 \mathrm{pM}
\end{aligned}
$$
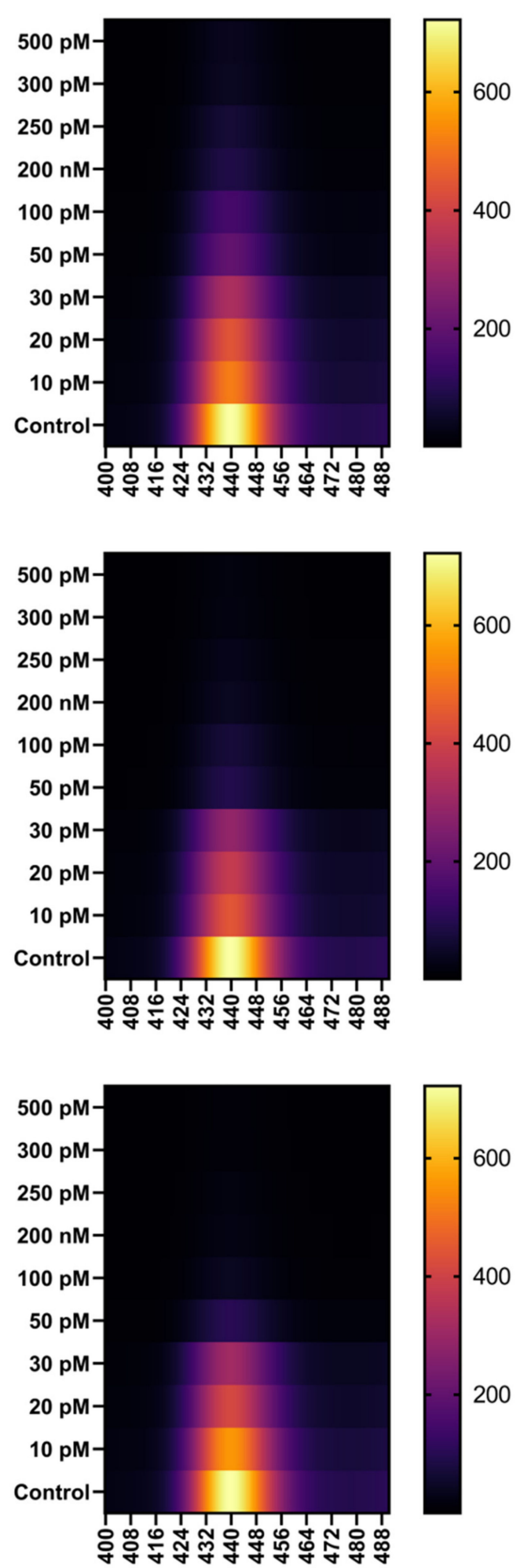

Figure 8. Fluorescence emission spectra of the $\mathrm{NH}_{2}-\mathrm{MIL}-53 @ \mathrm{H}_{2} \mathrm{TMP}$ in the presence of Anti-cas9 protein, sgRNA, and ssDNA.

As mentioned before, the used porphyrin, $\mathrm{H}_{2} \mathrm{TMP}$, has a rigid structure; therefore, its conformation is not affected by phase changes and/or solvent changes. Therefore, any fluorescent changes in these experiments come from the interactions between them. In this section, the ability of the prepared fluorescent-active nanostructure in detection of low concentrations of recombinant-SARS-CoV-2 spike antigens are investigated (Figure 9). 
Based on the literature, there are no studies using simple, cost-effective, and tunable nanomaterial to detect trace amounts of recombinant-SARS-CoV-2 spike antigens. Therefore, the detection range of 5 to $300 \mathrm{nM}$ is highly competitive/novel/superior and can be considered an advantage. By the addition of different concentrations of recombinant-SARS-CoV-2 spike antigens to the substrate, the fluorescence spectra decay in a predictable manner with a linear slope; therefore, this detection method can be used for clinical trials.

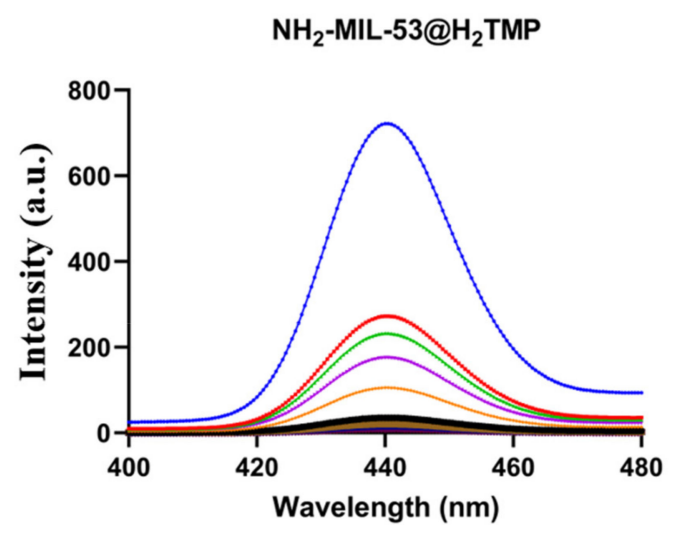

Figure 9. Fluorescence emission spectra of the $\mathrm{NH}_{2}-\mathrm{MIL}-53 @ \mathrm{H}_{2} \mathrm{TMP}$ in the presence of recombinant SARS-CoV-2 spike antigen.

Recombinant SARS-CoV-2
Spike Antigen
- Control
$-5 \mathrm{nM}$
$-10 \mathrm{nM}$
$-20 \mathrm{nM}$
$-30 \mathrm{nM}$
$-50 \mathrm{nM}$
$-100 \mathrm{nM}$
$-150 \mathrm{nM}$
$-200 \mathrm{nM}$
$-300 \mathrm{nM}$

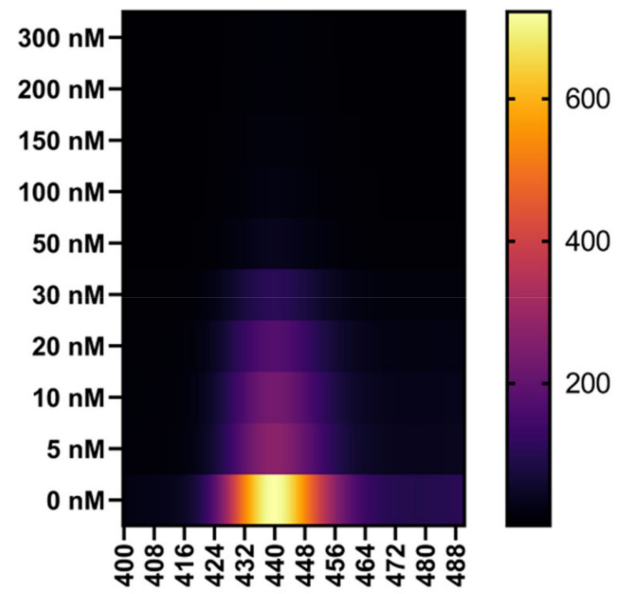

\section{Conclusions}

Herein, an unprecedented nanocomposite is synthesized based on a green and novel approach by blending the $\mathrm{NH}_{2}$-MIL-53 and porphyrins, which were fully characterized. The porphyrins were decorated on the surface of $\mathrm{NH}_{2}-\mathrm{MIL}-53$ by coating the surface of $\mathrm{NH}_{2}$-MIL-53 with leaf extracts, which enabled different types of interactions, including hydrogen bonding, van der Waals, and $\pi-\pi$ interactions. The synthesized nanomaterial, $\mathrm{NH}_{2}$-MIL-53@ $\mathrm{H}_{2} \mathrm{TMP}$, was applied for the detection of ultra-trace concentrations of ssDNA, sgRNA, anti-cas9 proteins, and recombinant SARS-CoV-2 spike antigen. All of them showed the unprecedented limit of detection of about $10 \mathrm{pM}$ for the genetic materials/proteins and below $10 \mathrm{nM}$ for the recombinant SARS-CoV-2 spike antigen. The potential cytotoxicity of the $\mathrm{NH}_{2}-\mathrm{MIL}-53 @ \mathrm{H}_{2} \mathrm{TMP}$ and its counterparts was assessed by MTT assay. The results showed that by incorporating the porphyrins on the surface, the nanocomposite was endowed with enhanced biocompatibility and was in a safer format in almost all of the cell lines and at various concentrations; however, in some cases, these differences were too low to be meaningful.

Supplementary Materials: The following are available online at https:/ / www.mdpi.com/article / 10.3390/biom11111714/s1, Figure S1: PXRD pattern for the synthesized MOF, Figure S2: FTIR spectra for the synthesized MOF, Figure S3: Elemental mapping for the synthesized MOF via high-gravity and the use of leaf extracts.

Author Contributions: Conceptualization, N.R., M.R. and R.S.V.; methodology, N.R., M.S., F.R. and S.S.; software, N.R. and Y.F.; validation, N.R., S.S., H.D., S.A., S.M. and M.B.; formal analysis, N.R., S.S. and H.D.; investigation, N.R.; resources, N.R., R.D. and R.S.V.; data curation, N.R. and Y.F.; writing—original draft preparation, N.R., M.R., S.S., S.A., S.M., M.B., H.D., M.S., Y.F., F.R. and E.M.; writing—review and editing, N.R., M.R., S.S., S.A., S.M., M.B., H.D., M.S., Y.F., F.R. and E.M.; visualization, Y.F. and R.D.; supervision, N.R., M.R., R.S.V. and E.M.; project administration, N.R.; All authors have read and agreed to the published version of the manuscript.

Funding: No funding was received for this work.

Institutional Review Board Statement: Not applicable.

Informed Consent Statement: Not applicable. 
Data Availability Statement: All data presented in this manuscript as well as complementary information will be available upon request from Navid Rabiee (N.R.); nrabiee94@gmail.com or navid.rabiee@mq.edu.au.

Conflicts of Interest: The authors declare no conflict of interest.

Sample Availability: Samples of outcomes are available as upon request from Navid Rabiee (N.R.); nrabiee94@gmail.com or navid.rabiee@mq.edu.au.

\section{References}

1. Mukherjee, P.; Kumar, A.; Bhamidipati, K.; Puvvada, N.; Sahu, S.K. Facile Strategy to Synthesize Magnetic Upconversion Nanoscale Metal-Organic Framework Composites for Theranostics Application. ACS Appl. Bio Mater. 2019, 3, 869-880. [CrossRef]

2. Jin, M.; Mou, Z.-L.; Zhang, R.-L.; Liang, S.-S.; Zhang, Z.-Q. An efficient ratiometric fluorescence sensor based on metal-organic frameworks and quantum dots for highly selective detection of 6-mercaptopurine. Biosens. Bioelectron. 2017, 91, 162-168. [CrossRef] [PubMed]

3. Liu, Z.; Feng, H.; Xue, S.; Xie, P.; Li, L.; Hou, X.; Gong, J.; Wei, X.; Huang, J.; Wu, D. The triple-component $\mathrm{Ag}_{3} \mathrm{PO}_{4}-\mathrm{CoFe}_{2} \mathrm{O}_{4}-\mathrm{GO}$ synthesis and visible light photocatalytic performance. Appl. Surf. Sci. 2018, 458, 880-892. [CrossRef]

4. Nasseri, B.; Soleimani, N.; Rabiee, N.; Kalbasi, A.; Karimi, M.; Hamblin, M.R. Point-of-care microfluidic devices for pathogen detection. Biosens. Bioelectron. 2018, 117, 112-128. [CrossRef]

5. Farjadian, F.; Moghoofei, M.; Mirkiani, S.; Ghasemi, A.; Rabiee, N.; Hadifar, S.; Beyzavi, A.; Karimi, M.; Hamblin, M.R. Bacterial components as naturally inspired nano-carriers for drug/gene delivery and immunization: Set the bugs to work? Biotechnol. Adv. 2018, 36, 968-985. [CrossRef]

6. $\quad$ Rabiee, N.; Yaraki, M.T.; Garakani, S.M.; Garakani, S.M.; Ahmadi, S.; Lajevardi, A.; Bagherzadeh, M.; Rabiee, M.; Tayebi, L.; Tahriri, M. Recent advances in porphyrin-based nanocomposites for effective targeted imaging and therapy. Biomaterials 2020, 232, 119707. [CrossRef]

7. Ahmadi, S.; Rabiee, N.; Bagherzadeh, M.; Elmi, F.; Fatahi, Y.; Farjadian, F.; Baheiraei, N.; Nasseri, B.; Rabiee, M.; Dastjerd, N.T. Stimulus-responsive sequential release systems for drug and gene delivery. Nano Today 2020, 34, 100914. [CrossRef]

8. Nik, A.B.; Zare, H.; Razavi, S.; Mohammadi, H.; Ahmadi, P.T.; Yazdani, N.; Bayandori, M.; Rabiee, N.; Mobarakeh, J.I. Smart drug delivery: Capping strategies for mesoporous silica nanoparticles. Microporous Mesoporous Mater. 2020, $299,110115$.

9. Maghsoudi, S.; Shahraki, B.T.; Rabiee, N.; Fatahi, Y.; Dinarvand, R.; Tavakolizadeh, M.; Ahmadi, S.; Rabiee, M.; Bagherzadeh, M.; Pourjavadi, A. Burgeoning polymer nano blends for improved controlled drug release: A review. Int. J. Nanomed. 2020, 15, 4363. [CrossRef]

10. Rabiee, N.; Bagherzadeh, M.; Kiani, M.; Ghadiri, A.M. Rosmarinus officinalis directed palladium nanoparticle synthesis: Investigation of potential anti-bacterial, anti-fungal and Mizoroki-Heck catalytic activities. Adv. Powder Technol. 2020, 31, 1402-1411. [CrossRef]

11. Bagherzadeh, M.; Rabiee, N.; Fattahi, Y.; Dinarvand, R. Zn-rich (GaN) 1-x (ZnO) x: A biomedical friend? New J. Chem. 2021, 45, 4077-4089. [CrossRef]

12. Spampinato, V.; Parracino, M.A.; La Spina, R.; Rossi, F.; Ceccone, G. Surface analysis of gold nanoparticles functionalized with thiol-modified glucose SAMs for biosensor applications. Front. Chem. 2016, 4, 8. [CrossRef]

13. Rogers, J.K.; Taylor, N.D.; Church, G.M. Biosensor-based engineering of biosynthetic pathways. Curr. Opin. Biotechnol. 2016, 42, 84-91. [CrossRef]

14. Velasco-Garcia, M.N.; Mottram, T. Biosensor technology addressing agricultural problems. Biosyst. Eng. 2003, 84, 1-12. [CrossRef]

15. Flachbart, L.K.; Sokolowsky, S.; Marienhagen, J. Displaced by deceivers: Prevention of biosensor cross-talk is pivotal for successful biosensor-based high-throughput screening campaigns. ACS Synth. Biol. 2019, 8, 1847-1857. [CrossRef]

16. Zhu, P.; Li, S.; Zhou, S.; Ren, N.; Ge, S.; Zhang, Y.; Wang, Y.; Yu, J. In situ grown COFs on 3D strutted graphene aerogel for electrochemical detection of NO released from living cells. Chem. Eng. J. 2020, 420, 127559. [CrossRef]

17. Zhu, P.; Li, S.; Zhao, C.; Zhang, Y.; Yu, J. 3D synergistical rGO/Eu (TPyP)(Pc) hybrid aerogel for high-performance $\mathrm{NO}_{2}$ gas sensor with enhanced immunity to humidity. J. Hazard. Mater. 2020, 384, 121426. [CrossRef]

18. Nasr, S.M.; Rabiee, N.; Hajebi, S.; Ahmadi, S.; Fatahi, Y.; Hosseini, M.; Bagherzadeh, M.; Ghadiri, A.M.; Rabiee, M.; Jajarmi, V. Biodegradable nanopolymers in cardiac tissue engineering: From concept towards nanomedicine. Int. J. Nanomed. 2020, $15,4205$. [CrossRef]

19. Rabiee, N.; Ahmadvand, S.; Ahmadi, S.; Fatahi, Y.; Dinarvand, R.; Bagherzadeh, M.; Rabiee, M.; Tahriri, M.; Tayebi, L.; Hamblin, M.R. Carbosilane dendrimers: Drug and gene delivery applications. J. Drug Deliv. Sci. Technol. 2020, 59, 101879. [CrossRef]

20. Rabiee, N.; Bagherzadeh, M.; Kiani, M.; Ghadiri, A.M.; Etessamifar, F.; Jaberizadeh, A.H.; Shakeri, A. Biosynthesis of copper oxide nanoparticles with potential biomedical applications. Int. J. Nanomed. 2020, 15, 3983. [CrossRef]

21. Kiani, M.; Rabiee, N.; Bagherzadeh, M.; Ghadiri, A.M.; Fatahi, Y.; Dinarvand, R.; Webster, T.J. High-gravity-assisted green synthesis of palladium nanoparticles: The flowering of nanomedicine. Nanomed. Nanotechnol. Biol. Med. 2020, $30,102297$. [CrossRef]

22. Saeb, M.R.; Rabiee, N.; Mozafari, M.; Mostafavi, E. Metal-organic frameworks-based nanomaterials for drug delivery. Materials 2021, 14, 3652. [CrossRef] 
23. Rabiee, N.; Bagherzadeh, M.; Ghadiri, A.M.; Kiani, M.; Aldhaher, A.; Ramakrishna, S.; Tahriri, M.; Tayebi, L.; Webster, T.J. Green synthesis of ZnO NPs via Salvia hispanica: Evaluation of potential antioxidant, antibacterial, mammalian cell viability, H1N1 influenza virus inhibition and photocatalytic activities. J. Biomed. Nanotechnol. 2020, 16, 456-466. [CrossRef]

24. Tavakolizadeh, M.; Pourjavadi, A.; Ansari, M.; Tebyanian, H.; Tabaei, S.J.S.; Atarod, M.; Rabiee, N.; Bagherzadeh, M.; Varma, R.S. An environmentally friendly wound dressing based on a self-healing, extensible and compressible antibacterial hydrogel. Green Chem. 2021, 23, 1312-1329. [CrossRef]

25. Rajeev, G.; Melville, E.; Cowin, A.J.; Prieto-Simon, B.; Voelcker, N.H. Porous alumina membrane-based electrochemical biosensor for protein biomarker detection in chronic wounds. Front. Chem. 2020, 8, 155. [CrossRef]

26. Sun, Z.; Wang, L.; Wu, S.; Pan, Y.; Dong, Y.; Zhu, S.; Yang, J.; Yin, Y.; Li, G. An Electrochemical Biosensor Designed by Using Zr-Based Metal-Organic Frameworks for the Detection of Glioblastoma-Derived Exosomes with Practical Application. Anal. Chem. 2020, 92, 3819-3826. [CrossRef]

27. Saeed, A.A.; Sánchez, J.L.A.; O'Sullivan, C.K.; Abbas, M.N. DNA biosensors based on gold nanoparticles-modified graphene oxide for the detection of breast cancer biomarkers for early diagnosis. Bioelectrochemistry 2017, 118, 91-99. [CrossRef] [PubMed]

28. Kalkal, A.; Pradhan, R.; Kadian, S.; Manik, G.; Packirisamy, G. Biofunctionalized Graphene Quantum Dots Based Fluorescent Biosensor toward Efficient Detection of Small Cell Lung Cancer. ACS Appl. Bio Mater. 2020, 3, 4922-4932. [CrossRef]

29. Kumar, S.; Tripathy, S.; Jyoti, A.; Singh, S.G. Recent advances in biosensors for diagnosis and detection of sepsis: A comprehensive review. Biosens. Bioelectron. 2019, 124, 205-215. [CrossRef] [PubMed]

30. Maghsoudi, S.; Rabiee, N.; Ahmadi, S.; Rabiee, M.; Bagherzadeh, M.; Karimi, M. An overview of microfluidic devices. Biomed. Appl. Microfluid. Devices 2021, 1-22. [CrossRef]

31. Rabiee, N.; Bagherzadeh, M.; Heidarian Haris, M.; Ghadiri, A.M.; Matloubi Moghaddam, F.; Fatahi, Y.; Dinarvand, R.; Jarahiyan, A.; Ahmadi, S.; Shokouhimehr, M. Polymer-Coated $\mathrm{NH}_{2}-\mathrm{UiO}-66$ for the Codelivery of DOX/pCRISPR. ACS Appl. Mater. Interfaces 2021, 13, 10796-10811. [CrossRef]

32. Shahraki, B.T.; Maghsoudi, S.; Fatahi, Y.; Rabiee, N.; Bahadorikhalili, S.; Dinarvand, R.; Bagherzadeh, M.; Verpoort, F. The flowering of mechanically interlocked molecules: Novel approaches to the synthesis of rotaxanes and catenanes. Coord. Chem. Rev. 2020, 423, 213484. [CrossRef]

33. Rabiee, N.; Bagherzadeh, M.; Jouyandeh, M.; Zarrintaj, P.; Saeb, M.R.; Mozafari, M.; Shokouhimehr, M.; Varma, R.S. Natural Polymers Decorated MOF-MXene Nanocarriers for Co-delivery of Doxorubicin/pCRISPR. ACS Appl. Bio Mater. 2021, 4, 5106-5121. [CrossRef]

34. Pourjavadi, A.; Tavakolizadeh, M.; Hosseini, S.H.; Rabiee, N.; Bagherzadeh, M. Highly stretchable, self-adhesive, and selfhealable double network hydrogel based on alginate/polyacrylamide with tunable mechanical properties. J. Polym. Sci. 2020, 58, 2062-2073. [CrossRef]

35. Rabiee, N.; Bagherzadeh, M.; Ghadiri, A.M.; Salehi, G.; Fatahi, Y.; Dinarvand, R. ZnAl nano layered double hydroxides for dual functional CRISPR/Cas9 delivery and enhanced green fluorescence protein biosensor. Sci. Rep. 2020, 10, 1-15. [CrossRef]

36. Hajebi, S.; Mohammadi Nasr, S.; Rabiee, N.; Bagherzadeh, M.; Ahmadi, S.; Rabiee, M.; Tahriri, M.; Tayebi, L.; Hamblin, M.R. Bioresorbable composite polymeric materials for tissue engineering applications. Int. J. Polym. Mater. Polym. Biomater. 2020, 69, 1-15. [CrossRef]

37. Rabiee, N.; Bagherzadeh, M.; Tavakolizadeh, M.; Pourjavadi, A.; Atarod, M.; Webster, T.J. Synthesis, characterization and mechanistic study of nano chitosan tetrazole as a novel and promising platform for CRISPR delivery. Int. J. Polym. Mater. Polymeric Biomater. 2020, 69, 1-11. [CrossRef]

38. Kharati, M.; Rabiee, M.; Rostami-Nejad, M.; Aghamohammadi, E.; Asadzadeh-Aghdaei, H.; Zali, M.R.; Rabiee, N.; Fatahi, Y.; Bagherzadeh, M.; Webster, T.J. Development of a nano biosensor for anti-gliadin detection for Celiac disease based on suspension microarrays. Biomed. Phys. Eng. Express 2020, 6, 55015. [CrossRef]

39. Maghsoudi, S.; Taghavi Shahraki, B.; Rabiee, N.; Fatahi, Y.; Bagherzadeh, M.; Dinarvand, R.; Ahmadi, S.; Rabiee, M.; Tahriri, M.; Hamblin, M.R. The colorful world of carotenoids: A profound insight on therapeutics and recent trends in nano delivery systems. Crit. Rev. Food Sci. Nutr. 2020, 60, 1-40. [CrossRef]

40. Rabiee, N.; Ahmadi, S.; Fatahi, Y.; Rabiee, M.; Bagherzadeh, M.; Dinarvand, R.; Bagheri, B.; Zarrintaj, P.; Saeb, M.R.; Webster, T.J. Nanotechnology-assisted microfluidic systems: From bench to bedside. Nanomedicine 2020, 16, 237-258. [CrossRef]

41. Ahmadi, S.; Rabiee, N.; Fatahi, Y.; Bagherzadeh, M.; Gachpazan, M.; Baheiraei, N.; Nasseri, B.; Karimi, M.; Webster, T.J.; Hamblin, M.R. Controlled gene delivery systems: Nanomaterials and chemical approaches. J. Biomed. Nanotechnol. 2020, 16, 553-582. [CrossRef] [PubMed]

42. Abu-Thabit, N.; Ratemi, E. Hybrid porous silicon biosensors using plasmonic and fluorescent nanomaterials: A mini review. Front. Chem. 2020, 8, 454. [CrossRef] [PubMed]

43. Ma, X.; Liu, H.; Yang, W.; Mao, G.; Zheng, L.; Jiang, H.L. Modulating Coordination Environment of Single-Atom Catalysts and Their Proximity to Photosensitive Units for Boosting MOF Photocatalysis. J. Am. Chem. Soc. 2021, 143, 12220-12229. [CrossRef]

44. Rabiee, N.; Bagherzadeh, M.; Ghadiri, A.M.; Fatahi, Y.; Aldhaher, A.; Makvandi, P.; Dinarvand, R.; Jouyandeh, M.; Saeb, M.R.; Mozafari, M. Turning Toxic Nanomaterials into a Safe and Bioactive Nanocarrier for Co-delivery of DOX/pCRISPR. ACS Appl. Bio Mater. 2021, 4, 5336-5351. [CrossRef]

45. Rabiee, N.; Bagherzadeh, M.; Ghadiri, A.M.; Fatahi, Y.; Baheiraei, N.; Safarkhani, M.; Aldhaher, A.; Dinarvand, R. Biomultifunctional noncovalent porphyrin functionalized carbon-based nanocomposite. Sci. Rep. 2021, 11, 1-15. [CrossRef] 
46. Jiao, Y.; Li, Z.; Ma, Y.; Zhou, G.; Wang, S.; Lu, G. The studies on gas adsorption properties of MIL-53 series MOFs materials. AIP Adv. 2017, 7, 085009. [CrossRef]

47. Hamon, L.; Serre, C.; Devic, T.; Loiseau, T.; Millange, F.; Férey Gr Weireld, G.D. Comparative study of hydrogen sulfide adsorption in the MIL-53 (Al, Cr, Fe), MIL-47 (V), MIL-100 (Cr), and MIL-101 (Cr) metal-organic frameworks at room temperature. J. Am. Chem. Soc. 2009, 131, 8775-8777. [CrossRef]

48. Rabiee, N.; Bagherzadeh, M.; Ghadiri, A.M.; Kiani, M.; Ahmadi, S.; Aldhaher, A.; Varma, R.S.; Webster, T.J. High-gravity-assisted green synthesis of NiO-NPs anchored on the surface of biodegradable nanobeads with potential biomedical applications. $J$. Biomed. Nanotechnol. 2020, 16, 520-530. [CrossRef]

49. Rabiee, N.; Bagherzadeh, M.; Kiani, M.; Ghadiri, A.M.; Zhang, K.; Jin, Z.; Ramakrishna, S.; Shokouhimehr, M. High gravityassisted green synthesis of $\mathrm{ZnO}$ nanoparticles via Allium ursinum: Conjoining nanochemistry to neuroscience. Nano Express 2020, 1, 020025. [CrossRef]

50. Ghadiri, A.M.; Rabiee, N.; Bagherzadeh, M.; Kiani, M.; Fatahi, Y.; Di Bartolomeo, A.; Dinarvand, R.; Webster, T.J. Green synthesis of CuO-and Cu2O-NPs in assistance with high-gravity: The flowering of Nanobiotechnology. Nanotechnology 2020, $31,425101$. [CrossRef]

51. Han, L.; Zhang, J.; Mao, Y.; Zhou, W.; Xu, W.; Sun, Y. Facile and green synthesis of MIL-53 (Cr) and its excellent adsorptive desulfurization performance. Ind. Eng. Chem. Res. 2019, 58, 15489-15496. [CrossRef]

52. Du, J.-J.; Yuan, Y.-P.; Sun, J.-X.; Peng, F.-M.; Jiang, X.; Qiu, L.-G.; Xie, A.-J.; Shen, Y.-H.; Zhu, J.-F. New photocatalysts based on MIL-53 metal-organic frameworks for the decolorization of methylene blue dye. J. Hazard. Mater. 2011, 190, 945-951. [CrossRef]

53. Walker, A.M.; Civalleri, B.; Slater, B.; Mellot-Draznieks, C.; Corà, F.; Zicovich-Wilson, C.M.; Román-Pérez, G.; Soler, J.M.; Gale, J.D. Flexibility in a metal-organic framework material controlled by weak dispersion forces: The bistability of MIL-53 (Al). Angew. Chem. 2010, 122, 7663-7665. [CrossRef]

54. Rabiee, N.; Ahmadi, S.; Afshari, R.; Khalaji, S.; Rabiee, M.; Bagherzadeh, M.; Fatahi, Y.; Dinarvand, R.; Tahriri, M.; Tayebi, L. Polymeric Nanoparticles for Nasal Drug Delivery to the Brain: Relevance to Alzheimer's Disease. Adv. Ther. 2020, 4, 2000076. [CrossRef]

55. Rabiee, N.; Ahmadi, S.; Arab, Z.; Bagherzadeh, M.; Safarkhani, M.; Nasseri, B.; Rabiee, M.; Tahriri, M.; Webster, T.J.; Tayebi, L. Aptamer hybrid nanocomplexes as targeting components for antibiotic/gene delivery systems and diagnostics: A review. Int. J. Nanomed. 2020, 15, 4237. [CrossRef]

56. Nour, S.; Baheiraei, N.; Imani, R.; Rabiee, N.; Khodaei, M.; Alizadeh, A.; Moazzeni, S.M. Bioactive materials: A comprehensive review on interactions with biological microenvironment based on the immune response. J. Bionic Eng. 2019, 16, 563-581. [CrossRef]

57. Bahrami, S.; Baheiraei, N.; Mohseni, M.; Razavi, M.; Ghaderi, A.; Azizi, B.; Rabiee, N.; Karimi, M. Three-dimensional graphene foam as a conductive scaffold for cardiac tissue engineering. J. Biomater. Appl. 2019, 34, 74-85. [CrossRef]

58. Nour, S.; Baheiraei, N.; Imani, R.; Khodaei, M.; Alizadeh, A.; Rabiee, N.; Moazzeni, S.M. A review of accelerated wound healing approaches: Biomaterial-assisted tissue remodeling. J. Mater. Sci. Mater. Med. 2019, 30, 1-15. [CrossRef]

59. Maghsoudi, S.; Shahraki, B.T.; Rabiee, N.; Afshari, R.; Fatahi, Y.; Dinarvand, R.; Ahmadi, S.; Bagherzadeh, M.; Rabiee, M.; Tayebi, L. Recent advancements in aptamer-bioconjugates: Sharpening stones for breast and prostate cancers targeting. J. Drug Deliv. Sci. Technol. 2019, 53, 101146. [CrossRef]

60. Kiani, M.; Rabiee, N.; Bagherzadeh, M.; Ghadiri, A.M.; Fatahi, Y.; Dinarvand, R.; Webster, T.J. Improved green biosynthesis of chitosan decorated Ag-and $\mathrm{Co}_{3} \mathrm{O}_{4}$-nanoparticles: A relationship between surface morphology, Photocatalytic and biomedical applications. Nanomed. Nanotechnol. Biol. Med. 2021, 32, 102331. [CrossRef] [PubMed]

61. Nasseri, B.; Kocum, I.C.; Seymen, C.M.; Rabiee, N. Penetration depth in nanoparticles incorporated radiofrequency hyperthermia into the tissue: Comprehensive study with histology and pathology observations. IET Nanobiotechnol. 2019, 13, 634-639. [CrossRef] [PubMed]

62. Zarghami, D.M.; Bagheri, B.; Nasiriasayesh, A.; Mashhadzadeh, A.H.; Zarrintaj, P.; Rabiee, N.; Bagherzadeh, M.; Habibzadeh, S.; Abida, O.; Saeb, M.R. Insight into the Self-Insertion of a Protein Inside the Boron Nitride Nanotube. ACS Omega 2020, 5 , 32051-32058. [CrossRef]

63. Nasseri, B.; Turk, M.; Kosemehmetoglu, K.; Kaya, M.; Piskin, E.; Rabiee, N.; Webster, T.J. The pimpled gold nanosphere: A superior candidate for plasmonic photothermal therapy. Int. J. Nanomed. 2020, 15, 2903. [CrossRef] [PubMed]

64. Rabiee, M.; Ghasemnia, N.N.; Rabiee, N.; Bagherzadeh, M. Microfluidic Devices and Drug Delivery Systems. In Biomedical Applications of Microfluidic Devices; Elsevier: Amsterdam, The Netherlands, 2021; pp. 153-186.

65. Ahmadi, S.; Rabiee, N.; Bagherzadeh, M.; Karimi, M. Microfluidic Devices for Gene Delivery Systems. In Biomedical Applications of Microfluidic Devices; Elsevier: Amsterdam, The Netherlands, 2021; pp. 187-208.

66. Pescitelli, G.; Gabriel, S.; Wang, Y.; Fleischhauer, J.; Woody, R.W.; Berova, N. Theoretical Analysis of the Porphyrin-Porphyrin Exciton Interaction in Circular Dichroism Spectra of Dimeric Tetraarylporphyrins. J. Am. Chem. Soc. 2003, 125, 7613-7628. [CrossRef] [PubMed] 